texture of the heart has been weakened by carditis or endocarditis, appears evident from the details of a case, in which inflammatory exudation on the lining mem. brane of this organ co-existed with inflammatory softening of its whole structure at the apex, and in which, at this point, a considerable degree of attenu. ation had taken place, which might no doubt, after some time, have gone on to rupture.-Ibid.

6. Perforating Ulcer of the Stomach.-Of the patients labouring under this disease, noticed by $\mathrm{Jaksch}$, thirtythree had acute tubercle of the lungs, twenty-six chronic tubercle of the lungs, and forty-three pneumonia. He therefore presumes that some relation exists between the affection in question and diseases of the lung. The same physician gives the following sketch of the symptoms commonly observed with this kind of ulceration. After intense mental or bodily exertion, or the use of some stimulating liquor or article of food, the patient complains of violent pain, extending upwards from the pit of the stomach, which often disappears after romiting. The tongue still remains clean, the appetite is variously altered, and the bowels are for the most part obstiuately costire. Sometimes the symptoms assume more of the character of those which accompany mucous gastritis. There is a dull persistent pain in the epigastrium, pyrosis, indigestion, romiting, and tumefaction of the abdomen. Jaksch, in speaking of the treatment of these cases, recommends the use of milk, veal soup, and chicken soup, as articles of diet. He also recommends, as palliative remedies, leeching and counter-irritation of the epigastric region, anodynes, the acetate of lead, and iron.Ilid.

\section{ABSTRACT OF THE PROCEEDINGS OF THE} ACADEMIE DE MEDECINE, PARIS.

The most interesting memoirs presented to this Academy during the past month are the following:ORGAN OF SPEECH.

M. Bouillaud read a paper entitled " New Researches, destined to shew that the faculty of Articulate Speech resides in the Anterior Lobes of the Cerebrum," in which he considers that he has established,-lst, that severe lesions of the anterior lobes of the brain constantly produce an alteration in the speech, varying from slight disturbance to complete loss of the faculty ; 2nd, that disease of the middle and posterior lobes, without implication of the anterior portions, do not affect the speech. From these propositions, M. Bouillaud deduces two corollaries; one respecting diagnosis, - viz., that whenever the speech is more or less affected from disease of the brain, it may be affirmed that the lesion exists in the anterior lobes; another respecting treatment, that if it be necessary to apply remedies as near as possible to the seat of the disease, as the trepan, for example, the forehead is the site to be chosen. The views, of $M$. Bouillaud were warmly contested by MM. Rochoux, Baillarger, \&c.

M. Chevallier presented a memoir on the "Presence of Amenic in certain Mineral Waters."

M. Monneret, one of the Commission sent to the
East to watch the progress of cholers, reported his experience of the disease in Constantinople. Nothing of importance was elicited.

M. Dubourg presented a memoir on "Symptomatic Abscess of the Inguinal Region," with the principal object of recommending free opening in preference to repeated punctures.

\section{ABSTRACT OF THE PROCEERINGS OF THE ACADEMIE DES SCIENCES, PARIS.}

M. Poggiale lectured on the properties of aldehyde, a new anæsthetic agent. He stated that it produced insensibility more rapidly than either æther or chloroform, and in animals had been exhibited withont producing any accident.

M. Gaudichaud exhibited a new alimentary ptant, received from America, which he called picquotiane. It contains a large amount of farina, and is the principal food of some of the aboriginal tribes of central America.

\section{TREATMENT OF HYDROPHOBIA IN THE} LAST CENTURY.

METHOD OF TREATING THOSE THAT HAVE BEEN UNDER MY CARE FOR THE BITE OF A MAD DOG, OR OTHER MAD ANIMAL.

If the person's constitution will bear the loss of blood, I take from him 8,10 , or 12 ounces, as soon as possible, and immediately after give him a draught with manna and salts, dissolv'd in an infusion of senna, enough to give five or six stools, and repeat it once a week for the first month. The next morning I prepare for him the following powders:-Loaf Sugar three drams, Salt Petre two drams, Sal Ammoniac one dram and half, made into fine powder, and mixed together, two scruples of which (or as much as you can hold on a shilling,) may be given to a grown person, twice or three times a day, in some warm tea, for the first montb, and once or twice a day for the second month. When application hath been made within a fortnight, I have not once had occasion to use any other medicine, though some of them have been terribly wounded; but when it hath been longer omitted, and the dreadfull symptoms appear, such as violent pain and giddiness of the head, fearfullness and trembling at the least noise, a pain of the throat without swelling, which pain extends itself to the stomach, with great thirst, but can not prevail on them to drink, an hydrophobia, or fear of water, \&c. \&c. I then treat them as follows :-

August 12th, 1739. A young woman, of as robust a constitution as $I$ erer met with, about 26 years old, was bit by a dog, which after a few days' confinement died mad. Her master and [a] maid-servant were bit at the same time by the same dog : both of them applied to me the fourth day from their being bit. I did for them as above, and they felt no ill effects, but the other laugh'd at them for applying for such a trifle as she called it, and continued well untill the seventh day of September following. As she was in the orchard gathering of apples, she complained of such violent pain and giddiness in ber head, that she was obliged to 
quit her work and go bome to bed. A few hours after, as the family was at supper, she came down stairs with nothing on but her shift, quite void of sense, running at, and endeavouring to bite, every one she came near. The family left the room as soon as possible, but fearing she might hurt herself, two of the men returned, having put on thick gloves, and carrying before them a large hemp sheet, such as is generally used in winnowing : they threw it over her, and getting her down on the floor, bound her as they thought fit. All that night she had no interval of reason, but endeavoured to bite every thing near her, and made a very uncommon noise. The next morning they put on some of her cloaths, placed her astride on a pack saddle, bound her firmly to it, and brought her to my house, which was near five miles from the place she lived at; but on the road, when ever she came near any water, she would be exceedingly fearfull; and after she was at my house, on bringing a bason of water near her, she wd use her utmost endeavours to more from it, and by continuing it in her sight, she wd through herself into great agonies. I kept her in the house some hours, hopeing she might have some interval of reason, but none appearing, having good assistance, I with great difficulty took from her arm twenty ounces of blood, greatly inflamed, having previously put on over her head a woman's thick petticoat, tied close on the top of her head, and likewise round her neck, to prevent her biting, or casting saliva or spittle over us that might hurt us. When after bleeding I had secured her arm, I turned the pocket hole of the coat before her face, and laying her back, I so opened her mouth with an iron spatula that an assistant could drench her with some manna and salts, dissolved in as small a quantity of water as possible; but alas! as soon as it was in her stomach, she was so dreadfnlly convulsed, that had she not been tied it had been impossible to hold her for several minutes, which as soon as over she was again put on horseback as before, and carried to her father's, which was about a mile and half from. I sent by her friends a quantity of the above powders, to be given her every three or four hours, by force if they could not give it otherwise.

By the time she came to her father's house the physick had purged her briskly, and by six the next morning they had drenched her with five doses of the powder, and some time in the afternoon she seemed a little sensible, though she had not slept from the time she was seized. She now complained of her head, throat, and stomach; the hydraphobia still continued, and she would by no means be perswaded to take her medicines, or any kind of liquid, though she complained greatly of thirst, but were obliged to drench her as before, which wd hurry her prodigiously for some time after. She now lay more quiet, and did not attempt to bite 80 much as before, and her speech began to be more articulate. The night following she had no sleep, but by the next morning could bear the sight of water, and to have it held near her mouth, but could not prevail on her to taste it, for fear it would bring on the pain of her stomach. The afternoon following she was very sensible, ber pains almost gone, her thirst abated, and consented to take her prowders dry, and let them dissolve in her mouth, which she cd swallow without much pain, and sometimes wd eat a piece of dry cake. The next night she slept several hours, but not without hurrys, and the next morning she took her powders in some tea, encreasing the quantity of liquid every dose, and frequently took some water gruet, \&c., and in a few days was so well as to walk in the fields.

September ye 30th. Thinking all danger over, she went to a child feast in the neighbourhood, where eating heartily, and drinking too much strong beer, she was again seized the next day with all the former symptoms, as violent as ever. On being sent for she was blooded plentifully, and ten grains of turbith mineral given, mixed with a little conserve of roses, and as soon as its operation by romiting was over, gave her the powders every four hours. The next day; October ye 2nd, towards evening, gave her a second dose of turbith mineral, and ordered the powders to be continued. The next morning all symptoms being better, I gave ber only the powders, untill ye 4 th of October at night, when she took the third dose of turbith mineral, and thought she seemed quite recovered. She took the fourth dose of turbith ye ninth day, without any laxative after, yet her mouth was not sore with it. I advised her to take the powders twice a day for six weeks, and afterwards once a day for a month or six weeks longer, which she accordingly did, and being afterwards very carefull of what she eat or drank, she had no return, but hath enjoied a very good state of health, being since married, and hath a large fanily of children.

During each time she had the hydraphobia ber pulse varied greatly, sometimes so strong that I shod have triken off more blood, had they not in a few ininutes been so small and intermiting that $I$ was fearfull she was dying, when on a sudden they wd rise again, and beat as regular for some time as in a well person, and so wd be altering several times in one hour; neither was she ever free from a subsultus tendonum during the hydraphobia.

Since the above case I have met with three other persons who had the hydraphobia, \&c., as above, before I was applied to. Inmediately after bleeding I gave a dose of turbith mineral every, or every other day, unto the third or fourth time, according as the symptoms encreased or decreased, continuing the powders as in the above case. I have always charged those that were bit not to use any spirituous liquors, wine, strong beer, high seasoned meats, nor spices. I dressed the wounds as if bit by a dog that was not mad, only that if it was in a place where I could conveniently keep it open as an issue, I did so for sevl months. The first opportunity I had of giving the above powders, was in the month of June, 1724, since which time I have had under mine, and my apprentice's care, upwards of three hundred persons for the bite of mad dogs, cats, \&c., all which, by the blessing of God, on the above medicine, have been happily preserved, without failing in one case.

Crediton, September 11th, 1759.

JOHN DYER.

Purging Salts one ounce, Manna half an ounc dissolved in a tea cup of Senna Tea. 